Review began 12/02/2021 Review ended 12/07/2021 Published 12/12/2021

\section{() Copyright 2021}

Narula et al. This is an open access article distributed under the terms of the Creative Commons Attribution License CC-BY 4.0., which permits unrestricted use, distribution, and reproduction in any medium, provided the original author and source are credited.

\title{
Hyperhemolysis in the Setting of Mixed- Autoimmune Hemolytic Anemia: A Rare Complication of COVID-19
}

\author{
Sonya Narula ${ }^{1}$, Sean Winkle ${ }^{1}$, Kenneth Brand ${ }^{1}$, Farhan Shah ${ }^{1}$, Priscilla Fujikawa ${ }^{1}$, Tyler Truitt ${ }^{1}$, Mark \\ Currie $^{1}$ \\ 1. Internal Medicine, LewisGale Medical Center, Salem, USA
}

Corresponding author: Sonya Narula, sonya.narula@hcahealthcare.com

\begin{abstract}
Severe acute respiratory syndrome coronavirus 2 (SARS-CoV-2) is a novel human pathogen known for its predilection on the respiratory system. Herein, we present a unique case in which a patient developed hyperhemolysis in the setting of mixed autoimmune hemolytic anemia (AIHA) secondary to SARS-CoV-2. A 33-years-old male with a past medical history of resolved immune thrombocytopenic purpura (ITP) presented to the hospital with symptoms of jaundice after being infected with SARS-CoV-2. On admission, his $\mathrm{Hgb}$ was $12.5 \mathrm{~g} / \mathrm{dL}$. Lab results showed indirect bilirubin of $13 \mathrm{mg} / \mathrm{dL}, \mathrm{LDH}$ at $759 \mathrm{U} / \mathrm{L}$, haptoglobin <10, and the percent reticulocyte count was $2.33 \%$. A direct antiglobulin test (DAT) was also positive for C3, IgG, anti-E, in addition to both warm and cold autoantibodies. PCR was positive for COVID-19. Within two days of admission, his Hgb dropped to $5.9 \mathrm{~g} / \mathrm{dL}$. A total of seven units of packed red blood cell (pRBC) was required to achieve a $\mathrm{Hgb}$ of $6 \mathrm{~g} / \mathrm{dL}$ in 48 hours. Patients with preexisting hematological abnormalities have a propensity to develop AIHA in the setting of the virus. The majority of the cases described in the literature were associated with warm AIHA. Our patient tested positive for both warm and cold antibodies, which may partially explain the mechanism behind hyperhemolysis in our patient.
\end{abstract}

Categories: Allergy/Immunology, Infectious Disease, Hematology

Keywords: covid 19, autoimmune hemolytic anemia (aiha), hyperhemolysis syndrome, mixed autoimmune hemolytic anemia, immune thrombocytopenia purpura

\section{Introduction}

Severe acute respiratory syndrome coronavirus 2 (SARS-CoV-2) is an emerging human pathogen that is known to cause pneumonia, respiratory failure, and acute respiratory distress syndrome. While predominantly known for disease and complications involving the respiratory system, the pathology of the virus can cause sequelae to multiple organ systems [1]. To the best of our knowledge, there have been several cases of SARS-CoV-2-associated autoimmune hemolytic anemia (AIHA). Herein, we report a unique case of hyperhemolysis in the setting of the virus.

\section{Case Presentation}

A 33-year-old male with a past medical history of resolved immune thrombocytopenic purpura (ITP) presented to the hospital with acute onset "yellow eyes" and "orange urine" associated with a week of fevers, chills, and night sweats. This was associated with malaise, loss of taste and smell, cough, and shortness of breath. He presented to our hospital before the advent of SARS-CoV-2 vaccines.

On initial presentation the patient's vital signs were normal. Labs were significant for bilirubin of $10 \mathrm{mg} / \mathrm{dL}$; other liver enzymes were unremarkable. He had leukocytosis with a white blood cell count (WBC) of $15 \times$ $103 / \mu \mathrm{L}$, however, hemoglobin (Hgb) and platelet count (Plt) were normal. Polymerase chain reaction (PCR) for SARS-CoV-2 was negative. The only significant physical exam finding was scleral icterus.

Overnight, the patient reported night sweats, nausea, and non-bloody and non-bilious emesis. Indirect and total bilirubin had increased to $13 \mathrm{mg} / \mathrm{dL}$ and $14 \mathrm{mg} / \mathrm{dL}$, respectively. His hemoglobin fell from $12.5 \mathrm{~g} / \mathrm{dL}$ to $8.7 \mathrm{~g} / \mathrm{dL}$. He was started on IV dexamethasone $4 \mathrm{mg}$ daily. A bone marrow biopsy was done due to concern for hemophagocytic lymphohistiocytosis, showing mild hemophagocytosis. An abdominal CT scan and a right upper quadrant ultrasound showed no hepatobiliary, pancreatic, or splenic involvement. Hemolysis labs results showed lactate dehydrogenase $(\mathrm{LDH})$ at $759 \mathrm{U} / \mathrm{L}$, Haptoglobin <10, ferritin $4903 \mathrm{ug} / \mathrm{L}$, and the percent reticulocyte count was $2.33 \%$.

Serologic testing performed for hepatitis, HIV, Echovirus, and cytomegalovirus were negative. The patient's mycoplasma IgM returned as positive, though the titer was $<770 \mathrm{U} / \mathrm{L}$. A repeat direct antiglobulin test (DAT) was positive for IgG, C3d, and on further testing, he was found to have a cold autoantibody and anti-E. His blood sample was reactive with three out of three cells in the antibody screen, and this patient had a complement activating IgM, causing red blood cell (RBC) lysis. At this point, IgG for SARS-CoV-2 also came 


\section{Cureus}

back positive. Hemolysis causing severe anemia ( $\mathrm{Hgb} 4.7 \mathrm{~g} / \mathrm{dL}$ ) led to intensive care unit transfer one day after being admitted (Table 1). In addition to further packed red blood cell (pRBC) transfusion, intravenous immunoglobulin (IVIG) was given with steroids in the ICU as well. A total of seven units of pRBC was required to achieve a $\mathrm{Hgb}$ of $6.0 \mathrm{~g} / \mathrm{dL}$ in 48 hours. Transfer to an outside facility was required for possible plasmapheresis.

\begin{tabular}{|c|c|c|c|}
\hline & Reference range & Admission & Day 3 \\
\hline WBC $(/ \mu \mathrm{L})$ & $4.50-10.5$ & $15 \times 10^{3}$ & $74 \times 10^{3}$ \\
\hline HgB (g/dL) & $11.4-15.5$ & 12.5 & 4.7 \\
\hline Platelet $(/ \mu \mathrm{L})$ & 130-385 & $344 \times 10^{9}$ & $126 \times 10^{9}$ \\
\hline Sodium (mmol/L) & 135-145 & 136 & 136 \\
\hline Potassium (mmol/L) & $3.6-5.2$ & 4.4 & 4.6 \\
\hline Chloride (mmol/L) & 100-108 & 105 & 105 \\
\hline Bicarbonate (mmol/L) & $21-32$ & 25 & 25 \\
\hline BUN (mg/dL) & $7-18$ & 21 & 32 \\
\hline Creatinine (mg/dL) & 0.60 & 1.00 & 1.30 \\
\hline Glucose (mg/dL) & 74-106 & 119 & 141 \\
\hline AST (U/L) & $15-37$ & 58 & 168 \\
\hline ALT (U/L) & $13-61$ & 51 & 67 \\
\hline Alkaline phosphatase (U/L) & $45-117$ & 67 & 86 \\
\hline Total bilirubin (mg/dL) & 0.2 & 14 & 10.60 \\
\hline Direct bilirubin (mg/dL) & & 0.90 & \\
\hline LDH (U/L) & $84-246$ & 758 & \\
\hline Haptoglobin & & $<10$ & \\
\hline Ferritin (ng/mL) & $26-388$ & 4903 & \\
\hline Reticulocyte count & & $2.3 \%$ & \\
\hline Mycoplasma lgM & & $<770$ & \\
\hline ESR & & $100 \mathrm{~mm} /$ hour & \\
\hline
\end{tabular}

TABLE 1: Laboratory values during days 1 and 3

At the outside facility, he was febrile to $39.1^{\circ} \mathrm{C}$, blood pressure was $134 / 74$, heart rate 74 , and respiratory rate of 35 . His $\mathrm{Hgb}$ was $3.0 \mathrm{~g} / \mathrm{dL}$, WBC $74 \times 10^{3} / \mathrm{hL}$, and Plt $363 \times 10^{9} / \mathrm{L}$ without evidence of overt bleeding. On the complete metabolic panel, his creatinine had risen to $1.34 \mathrm{mg} / \mathrm{dL}$, AST of $303 \mu / \mathrm{L}$, ALT $72 \mu / \mathrm{L}$, and alkaline phosphatase $100 \mathrm{U} / \mathrm{L}$, total bilirubin of $10.1 \mathrm{mg} / \mathrm{dL}$, and conjugated bilirubin of $1.8 \mathrm{mg} / \mathrm{dL}$. His reticulocyte count was $1.6 \%$. He tested positive for SARS-CoV-2 via PCR. The patient was started on rituximab in addition to IVIG and methylprednisone. He received $1 \mathrm{U}$ pRBC, but he rapidly deteriorated and developed multiorgan failure and coagulopathy with disseminated intravascular coagulation. His electrocardiogram showed anterolateral and inferior ischemia. He subsequently developed cardiac arrest. Massive transfusion protocol was initiated, and he received $4 \mathrm{U}$ pRBC. However, he ultimately died from shock secondary to a hyperhemolytic state.

\section{Discussion}

AIHA following SARS-CoV-2 infection with either warm or cold autoantibodies has previously been documented in the literature [2]. The majority of the cases described in the literature were associated with warm AIHA [3]. To the best of our knowledge, this has been the first case in which a patient had tested positive for both warm and cold antibodies. Previously reported median time between the onset of SARSCoV-2 and symptoms of AIHA was nine days, and the range was anywhere between 4 and 13 days [2]. Our 
patient presented to our hospital 14 days after his initial symptom of cough. Some of the reported cases of SARS-CoV-2 associated AIHA had a history of a prior hematological disorder. This suggests that preexisting hematological abnormalities may be a risk factor in the development of AIHA. These patients were treated with a combination of steroids and/or IVIG with the addition of rituximab in refractory cases [2].

This patient presented with an unusual complication known as hyperhemolysis. Hyperhemolysis is a type of delayed hemolytic transfusion reaction in which there is both hemolysis of transfused RBCs as well as the recipient's RBCs. Though originally described in AIHA, it has most commonly been observed in sickle-cell disease (SCD) patients who have required multiple transfusions [4]. Since hyperhemolysis is typically seen with complement activation of the membrane attack complex, which is uncommon in IgG predominant AIHA, it is likely that the patient's presentation with mixed warm-cold antibodies triggered his pathology.

SARS-CoV-2 may trigger AIHA through molecular mimicry, in which antibodies attack self-antigens due to shared sequences between foreign antigens and self-antigens. Ankyrin-1 is an erythrocyte membrane protein whose main function is to provide a connection between the membrane skeleton and plasma membrane. This protein shares a putative immunogenic antigenic epitope with $100 \%$ identity with a SARSCoV-2 surface glycoprotein known as spike protein [5]. In addition to this, it has been postulated that a modification of the surface of the RBC occurs during the course of the infection and hyperinflammation may further enhance complement deposition [6]. This alteration of erythrocyte membrane protein may influence the degree of hemolysis in SARS-CoV-2 patients, however, to the best of our knowledge this has been only shown in vitro. Whether having some underlying hematological/oncological abnormality plays a role in the ability of the virus to modify the surface of the RBCs is yet to be determined.

Researchers have posited that systemic hyperinflammation leading to a cytokine storm is the underlying mechanism behind the mortality of SARS-CoV-2. Specifically, serum cytokine levels that have been found to be elevated in patients suffering from a SARS-CoV-2-associated cytokine storm include interleukin-1 $\beta$, interleukin-6, inducible protein-10, tumor necrosis factor, interferon- $\gamma$, macrophage inflammatory protein $1 \alpha$ and $1 \beta$, and vascular endothelial growth factor. Also, increased interleukin-6 (IL-6) levels have been strongly associated with a shorter survival amongst patients suffering from SARS-CoV-2 [7]. The use of IL-6 inhibitors like tocilizumab has been considered since researchers have noted high concentrations of proinflammatory cytokines, such as IL-6 in severe SARS-CoV-2 infections [8]. It has also been shown to be effective in patients who develop hyperhemolysis in the setting of SCD [9].

\section{Conclusions}

Of the cases of AIHA described in the literature, this is the first case of a patient who developed hyperhemolysis in the setting of mixed AIHA secondary to SARS-CoV-2 outside of SCD. Our patient tested positive for both warm and cold antibodies, which may partially explain the mechanism behind hyperhemolysis. This case highlights the importance of further monitoring of SARS-CoV-2 infections and study of the pathophysiology associated with extrapulmonary manifestations of the virus. As a better understanding of associated systemic disease is reported, practitioners will be more prepared to anticipate poor outcomes and treat patients accordingly.

\section{Additional Information \\ Disclosures}

Human subjects: Consent was obtained or waived by all participants in this study. Conflicts of interest: In compliance with the ICMJE uniform disclosure form, all authors declare the following: Payment/services info: All authors have declared that no financial support was received from any organization for the submitted work. Financial relationships: All authors have declared that they have no financial relationships at present or within the previous three years with any organizations that might have an interest in the submitted work. Other relationships: All authors have declared that there are no other relationships or activities that could appear to have influenced the submitted work.

\section{Acknowledgements}

The authors would like to thank LewisGale Medical Center and Virginia Commonwealth University for collaboration in the care of this patient.

\section{References}

1. Domecq JP, Lal A, Sheldrick CR, et al.: Outcomes of patients with coronavirus disease 2019 receiving organ support therapies: the international viral infection and respiratory illness universal study registry. Crit Care Med. 2021, 49:437-48. 10.1097/CCM.0000000000004879

2. Lazarian G, Quinquenel A, Bellal M, et al.: Autoimmune haemolytic anaemia associated with COVID-19 infection. Br J Haematol. 2020, 190:29-31. 10.1111/bjh.16794

3. AbouYabis AN, Bell GT: Hemolytic anemia complicating COVID-19 infection. J Hematol. 2021, 10:221-7. $10.14740 /$ ih 906

4. Gouveia ME, Soares NB, Santoro MS, de Azevedo FC: Hyperhemolysis syndrome in a patient with sickle cell 


\section{Cureus}

anemia: case report. Rev Bras Hematol Hemoter. 2015, 37:266-8. 10.1016/j.bjhh.2015.03.005

5. Angileri F, Légaré S, Marino Gammazza A, Conway de Macario E, Macario AJ, Cappello F: Is molecular mimicry the culprit in the autoimmune haemolytic anaemia affecting patients with COVID-19? $\mathrm{Br} \mathrm{J}$ Haematol. 2020, 190:e92-3. 10.1111/bjh.16883

6. Berzuini A, Bianco C, Paccapelo C, et al.: Red cell-bound antibodies and transfusion requirements in hospitalized patients with COVID-19. Blood. 2020, 136:766-8. 10.1182/blood.2020006695

7. Fajgenbaum DC, June CH: Cytokine storm. N Engl J Med. 2020, 383:2255-73. 10.1056/NEJMra2026131

8. Durán-Méndez A, Aguilar-Arroyo AD, Vivanco-Gómez E, et al.: Tocilizumab reduces COVID-19 mortality and pathology in a dose and timing-dependent fashion: a multi-centric study. Sci Rep. 2021, 11:19728. 10.1038/s41598-021-99291-z

9. Sivapalaratnam S, Linpower L, Sirigireddy B, Agapidou A, Jain S, Win N, Tsitsikas DA: Treatment of posttransfusion hyperhaemolysis syndrome in sickle cell disease with the anti-IL6R humanised monoclonal antibody Tocilizumab. Br J Haematol. 2019, 186:e212-4. 10.1111/bjh.16103 